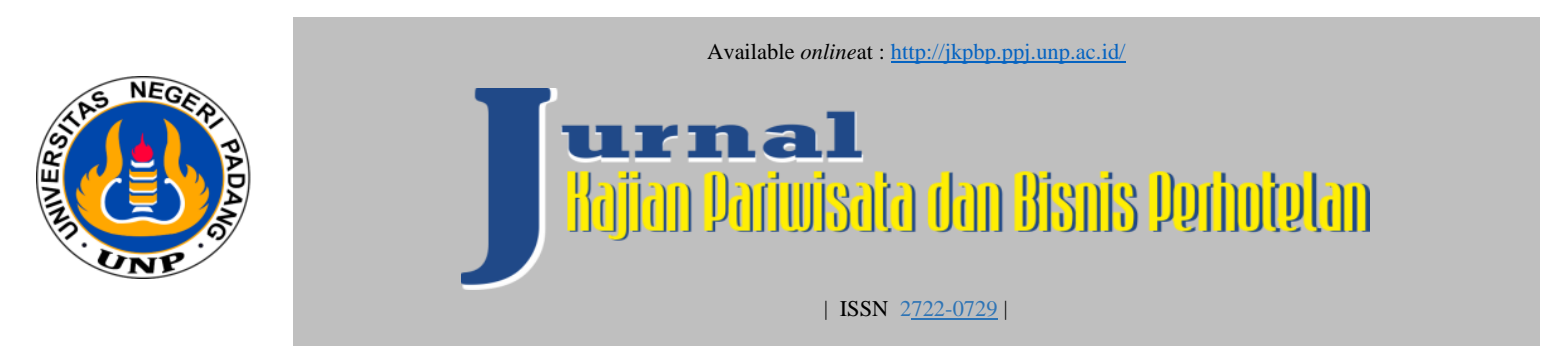

\title{
Pengaruh Kompensasi Terhadap Turnover Intention Karyawan Di Royal Denai Hotel Group Bukittinggi
}

\author{
Mirna Yolanda ${ }^{1}, Y o u m i l$ Abrian² \\ ${ }^{1}$ Universitas Negeri Padang \\ ${ }^{2}$ Universitas Negeri Padang \\ e-mail: mirnayolanda771@gmail.com, abrian.yomil@fpp.unp.ac.id
}

\begin{abstract}
Abstrak
Penelitian ini di latar belakangi dengan tingginya tingkat turnover karyawan, dan juga ditemukan keinginan karyawan untuk meninggalkan tempatnya bekerja sekarang. Tujuan-nya yaitu untuk mengetahui seberapa tinggi pengaruh Kompensasi terhadap Turnover Intention Karyawan di Royal Denai Group Bukittinggi. Penelitian dengan menggunakan deskriptif kuantitatif serta pendekatan assosiatif kausal. Beberapa karyawan Royal Denai Group Bukittinggi pada department Front Office, Housekeeping, F\&B Product, Food \& Baverage Service, Enginering, Sales \& Marketing, Accounting, $H R D$, dan Security dijadikan sebagai populasi. Jumlah data yang di gunakan berjumlah 94 orang. Metode pengambilan sampel menggunakan nonprobability dengan teknik sampling jenuh yaitu teknik pengambilan sampel yang memperlihatkan nilai kejenuhan sampel atau seluruh populasi dijadikan sebagai sampel, dimana seluruh karyawan di Royal Denai Hotel Group menjadi sampel dalam penelitian ini. [1]) Cara yang di pergunakan untuk mendapatkan hasil yang diperoleh dari data angket atau kuisioner yang kita sebar dengan diolah menggunakan bantuan SPSS.20 serta ditambah menggunakan skala likert. Teknik menganalisis data yang dipergunakan ialah deskriptif dan inferensial menggunakan analisis regresi linier sederhana. Hasilnya menyatakan: kompensasi di Royal Denai Hotel Group bukittinggi sebanyak 80,39\% menunjukkan kategori cukup. Sedangkan Turnover Intention di Royal Denai Hotel Group Bukittinggi menunjukkan bahwa sebanyak 72\%. Terdapat pengaruh yang signifikan antara kedua variabel di Royal Denai Group Bukittinggi dengan nilai regresi sebesar 0,281 dengan nilai t hitung 2.995 pada sig. $0,000<0,05$. Hal ini memiliki makna bahwa setiap tingkatan besaran 1 an kompensasi bisa membuat nilai turnover intention naik 0,281 satuan. Dapat dikatakan besaran pengaruh kompensasi dan turnover intention di Royal Denai Hotel Group Bukittinggi sebesar 79\%.
\end{abstract}

\section{Kata kunci :Kompensasi, Turnover Intention.}




\section{PENDAHULUAN}

Dalam bidang kepariwisataan memiliki prospek yang cukup berperan dalam sektor perekonomian Negara, dan masyarakat selain sektor-sektor ekonomi lainnya yang membantu devisa Negara. Kota Bukittinggi sebagai salah satu pusat daerah yang melambangkan kota wisata di Sumatera Barat sangat mengambil andil dalam proses penyediaan fasilitas wisata untuk para wisatawan, khususnya akomodasi perhotelan. [2]"Hotel merupakan usaha bisnis akomodasi dengan menyediakan jasa pelayanan penginapan bagi masyarakat umum dengan dilengkapi layanan makan dan minum, jasa pelayanan pembersihan kamar, layanan seragam, jasa pencucian pakaian,dan kelengkapan berbagai furniture dan kelengkapan yang dibutuhkan oleh tamu tentunya sesuai dengan kebijakan pemerintah".

Royal Denai Group Bukittinggi merupakan hotel berbintang yang memiliki Tiga bangunan Hotel aktif yang beroperasi. Hotel ini berjarak sekitar 15 menit dari pusat kota Bukittinggi. Hotel ini memiliki total keseluruhan 203 kamar.

Masalah individual yang terkait langsung dengan turnover intention adalah masalah kompensasi. Seorang karyawan yang merasa puas dengan apa yang di dapatkan sewaktu bekerja maka karyawan tersebut akan memutuskan untuk tetap bertahan pada suatu perusahaan dan mampu bekerja secara lebih efektif. Dengan kata lain, kompensasi memiliki arti penting bagi suatu perusahaan. Sehingga salah satu penentu supaya karyawan tidak beralih pandang dari tempatnya bekerja sekarang dengan memperhatikan besaran kompensasi yang dirasakan oleh karyawan. Sesuai dengan teori ahli, [3]'Kompensasi yaitu semua yang dihasilkan karyawan berupa uang maupun yang tidak berbentuk baik yang diterima secara di depan mata maupun melalui transferan dengan tanda terimakasih pekerjaan yang di berikan dari tempat bekerja".

[4]Banyak faktor mempengaruhi turnover intention diantaranya faktor psikologis/kesehan mental, faktor ekonomi/keuangan, dan faktor demografis/daerah. Hal ini dipicu dari beberapa [5]indikator turnover intention diantaranya pemikiran untuk mengundurkan diri, hasrat mencari peluang di tempat lain, dan keinginan untuk meninggalkan perusahaan. [6]Turnover Intention adalah kebiasaan seorang karyawan untuk mengkhianati perusahaan baik secara pribadi maupun kepurusan dari tempat bekerja yang bisa di sebabkan karena susah tidak memiliki gairah dalam bekerja di tempat yang terlalu lama atau sudah mendapatkan pekerjaan yanglebih baik. Beberapa temuan masalah tersebut diantaranya yaitu karyawan yang sering keberatan dengan adanya pemotongan pada gaji yang telah ditetapkan oleh perusahan untuk beberapa kebijakan yang telah ditetapkan oleh perusahaan. Contohnya dengan adanya pemotongan pada gaji untuk biaya kesehatan dan biaya kecelakaan pada saat bekerja. Sehingga dengan adanya pemotongan pada gaji yang diterima oleh karyawan terbilang kecil dan tidak memuaskan. Dimana banyak ditemukannya karyawan yang mengeluhkan akan kesempatan promosi atau naik jabatan. Tidak ada kesempatan untuk mendapatkan promosi atau naik jabatan, mayoritas dirasakan oleh karyawan tetap yang telah lama bekerja selama bertahun-tahun dengan masih di posisi yang sama. Selanjutnya mengenai pembayaran uang makan. Hotel tersebut tidak memiliki kantin sendiri bagi karyawan. Mereka memesan makanan dari luar atau lebih tepatnya menggunakan jasa cattering. Untuk pembayaran ini dilakukan dengan pemotongan gaji karyawan. Ditambah lagi dengan keluhan atas menu yang hampir sama setiap kali makan per shift.

Dengan demikian atas keluhan yang dirasakan oleh karyawan yang menyangkut kompensasi akan memungkinkan untuk keluar dari perusahaan (turnover intention) yang nantinya akan berujung pada turnover nyata. Penulis mengharapkan pihak perusahaan agar bisa menjadi bahan acuan dalam intropeksi/berbenah di sistem department peronalia Royal Denai Hotel Group Bukittinggi dalam melakukan strategi yang tepat untuk mencapai kepuasan karyawan agar tidak berkeinginan keluar (turnover Intention) dari perusahaan yang menyebabkan turnover. 


\section{METODOLOGI}

Penelitian ini digolongkan pada penelitian deskriptif kuantitatif menggunakan metode asosiatif kausal. [7]. Penelitian memiliki dua variabel yakni independent (Kompensasi) dan dependent (Turnover Intention). Penelitian ini mengambil karyawan yang bekerja di Royal Denai Group Bukittinggi dimana secara keseluruhan berjumlah 94 orang karyawan dan dijadikan sebagai populasi. [8] Teknik pengambilan sampel menggunakan metoda non probability dengan Sampling Jenuh dimana memakai teknik pemilihan yang memperhatikan nilai kejenuhan sampel, atau seluruh populasi dijadikan sebagai sampel. Jadi total sampel yang diambil adalah 94 sampel. Jenis data memakai data primer dan sekunder. Uji instrument yang digunakan pada penelitian ini yaitu uji validitas dan reliabilitas. Pengujian persyaratan dipakai yaitu uji normalitas, homogenitas dan linearitas. Teknik analisis yang di pakai adalah mentabulasi, deskripsi data. Pengujian hipotesis yang dipakai adalah uji regresi linear sederhana dan koefisien determinasi.

\section{HASIL PENELITIAN DAN PEMBAHASAN}

a. Deskripsi Data Tentang Kompensasi (X)

Data Kompensasi di dapatkan melalui 20 pernyataan yang telah diuji validitas serta realibitasnya, dapat dilihat sebagai berikut:

\begin{tabular}{|c|c|c|c|}
\hline Kategori & Kelas Interval & Frekuensi & $\mathbf{( \% )}$ \\
\hline Sangat Baik & $\geq 79.95$ & 4 & 4 \\
\hline Baik & $66.65-<79.95$ & 23 & 25 \\
\hline Kurang Baik & $\mathbf{5 3 . 3 5}-\mathbf{6 6 6 . 6 5}$ & $\mathbf{6 5}$ & $\mathbf{6 9}$ \\
\hline Buruk & $40.05-<53.35$ & 2 & 2 \\
\hline Sangat Buruk & $<40.05$ & 0 & 0 \\
\hline \multicolumn{2}{|c|}{ Total } & $\mathbf{9 4}$ & $\mathbf{1 0 0}$ \\
\hline
\end{tabular}

b. Deskripsi Data Tentang Turnover Intention (Y)

Berdasarkan data yang didapatkan hasil dari variabel Turnover Intention di Royal Denai Hotel Group Bukittinggi sebagai berikut:

\begin{tabular}{|c|c|c|c|}
\hline Kategori & Kelas Interval & Frekuensi & $(\boldsymbol{\%})$ \\
\hline Sangat Puas & $\geq 60$ & 3 & 4 \\
\hline Puas & $50-<60$ & 7 & 8 \\
\hline Kurang Puas & $\mathbf{4 0}-<\mathbf{5 0}$ & $\mathbf{4 4}$ & $\mathbf{4 6}$ \\
\hline Tidak Puas & $30-<40$ & 38 & 40 \\
\hline Sangat Tidak Puas & $<30$ & 2 & 2 \\
\hline \multicolumn{2}{|r}{ Total } & $\mathbf{9 4}$ & $\mathbf{1 0 0}$ \\
\hline
\end{tabular}

\section{Uji Persyaratan Analisis}

\section{Uji Normalitas}

Terdapat 4.28 Asymp Sig untuk variabel Kompensasi dan Turnover Intention adalah 0.889.

\section{Uji Homojenitas}

Terdapat nominal sig 0.463 pada taraf $>0.05$, maka nilai data lebih besar dari pencapaian signifikansi.

\section{Uji Linearitas}

Terdapat nilai sig. 0.048 dimana nominal itu menunjukkan $>0.05$, maka terdapat hubungan nilai linear secara signifikan antara kedua variabel.

\section{Pengujian Hipotesis}

Didapat nilai $\mathrm{F}$ hitung 8.969 dan nilai $\mathrm{T}$ 2.995. Maka model regresi bisa dipakai. Artinya Kompensasi berdampak signifikan pada turnover Intention. 
Coefficients $^{\mathrm{a}}$

\begin{tabular}{|c|c|c|c|c|c|}
\hline \multirow[t]{2}{*}{ Model } & \multicolumn{2}{|c|}{ Unstandardized Coefficients } & Standardized & \multirow[t]{2}{*}{$\mathrm{T}$} & \multirow[t]{2}{*}{ Sig. } \\
\hline & $B$ & Std. Error & Beta & & \\
\hline (Constant) & 23.040 & 6.197 & & 3.718 & .000 \\
\hline Kompensasi Karyawan & .281 & .094 & .298 & 2.995 & .004 \\
\hline
\end{tabular}

a. Dependent Variable: Turnover Intention Karyawan

Dari hasil olah data diatas maka di peroleh persamaan regresi yaitu:

$$
\mathbf{Y}=\mathbf{a}+\mathbf{b X}
$$

\section{$Y=23,040+0,281 X$}

Berdasarkan persamaan diatas di dapatkan koefisien regresi sebesar 0,281 dengan nilai sig. 0,000<0,05. Maknanya setiap peningkatan sebesar 1 an Kompensasi akan menaikkan 0,281 satuan Turnover Intention. Kemudian untuk melihat seberapa kuat variabel Kompensasi (X) terhadap Turnover Intention (Y) berpengaruh, maka dapat di perhatikan pada tabel berikut:

\section{Model Summary}

\begin{tabular}{|l|c|c|c|c|}
\hline Model & $\mathrm{R}$ & $\mathrm{R}$ Square & $\begin{array}{c}\text { Adjusted R } \\
\text { Square }\end{array}$ & $\begin{array}{c}\text { Std. Error of the } \\
\text { Estimate }\end{array}$ \\
\hline 1 & $.298^{\mathrm{a}}$ & .792 & .079 & 6.538 \\
\hline
\end{tabular}

a. Predictors: (Constant), Kompensasi Karyawan

b. Dependent Variable: Turnover Intention

Berdasarkan uraian diatas, di dapatkan nilai R Square sebesar 0,792 artinya pengaruh X terhadap Y adalah sebesar $79 \%$. Sedangkan $21 \%$ dipengaruhi oleh faktor lain. Maka Ha diterima \& Ho ditolak.

\section{Pembahasan}

\section{Kompensasi $(\mathrm{X})$}

Berdasarkan hasil pengolahan data dari 94 sampel, menggunakan SPSS versi 20.00. Diketahui bahwa variabel Kompensasi secara keseluruahan menunjukan persentase $65 \%$ pada rentang skor 53.35 - > 66.65 dengan kategori kurang baik. Dapat disimpulkan bahwa kompensasi di Royal Denai Hotel Group Bukittinggi secara keseluruhan dikategorikan dalam keadaan kurang baik.

[9]Kompensasi adalah sesuatu yang di dapatkan baik berbentuk uang, barang langsung atau tidak langsung yang diterima karyawan sebagai imbalan atas jasa yang diberikan oleh perusahaan. Sebab itu pihak memberikan kompensasi harus memperhatikan berapa yang di berikan kepada karyawan yang telah bekerja supaya karyawan merasa mendapatkan upah yang seimbang dengan apa yang dikerjakan dan akan membuat karayawan loyal terhadap perusahaan kita.

Kompensasi (X) dilihat dari 4 indikator yaitu: a) Tingkat Gaji dengan persentase $49 \%$ termasuk dalam kategori kurang baik, ada beberapa pendapat dari Karyawan meliputi: kurangnya gaji yang diterima dan tidak sesuai dengan hasil kerja yang telah dilakukan. b) indikator Reward dengan persentase $70 \%$ termasuk kategori kurang baik, dari informasi karyawan meliputi: kurangnya pemberian penghargaan/best employee, dan jarang memiliki program rekrasibagi karyawan yang bertujuan meningkatkan kekompakan. c) indikator Intensif dengan presentase $63 \%$ menunjukan kategori kurang baik, dengan data yang di terima dari karyawan meliputi: pemberian service yang terbilang masih kecil. d) indikator Tunjangan dengan persentase $49 \%$ menunjukan kategori kurang baik. Dari informasi yang di dapat karyawan meliputi: kurang adanya pemberian thr pada hari raya besar, pemotongan yang cukup besar pada bpjs kesehatan dan ketenagakerjaa. 
Berdasarkan penjelasan di atas variabel Kompensasi di Royal Denai Hotel Group Bukittinggi berada pada kategori kurang baik, dengan adanya maksud baik dalam menelaah permasalahan yang terjadi ini diharapkan dapat menjadi bayangan bagi Perusahaan Royal Denai Hotel Group Bukittinggi untuk memperbaiki serta memperhatikan pemberian kompensasi kepada karyawan dengan lebih baik lagi.

\section{Turnover Intention ( $\mathrm{Y}$ )}

Berdasarkan hasil pengolahan data dari 94 sampel, diketahui bahwa Turnover Intention Karyawan Royal Denai Hotel Group Bukittinggi secara keseluruhan menunjukan persentase sebesar 46\% pada rentang skor $40-<50$ dengan kategori kurang puas. Dengan demikian dapat disimpulkan bahwa Turnover Intention di Royal Denai Hotel Bukittinggi secara keseluruhan dikategorikan kurang baik. Hal ini sesuai dengan

Variabel Turnover Intention (Y) dilihat dari 3 indikator yaitu: a) Pemikiran Untuk Keluar berada pada kategori tidak puas dengan presentase $48 \%$, berdasarkan pernyataan data yang diperoleh dari pengunjung meliputi: terpenuhinya harapan karyawan, terpenuhinya tujuan dan keiinginan karyawan selama bekerja di suatu perusahaan. b) Keinginan Untuk Mencari Pekerjaan Lain berada pada kategori kurang puas dengan persentase $44 \%$, berdasarkan pernyataan data yang diperoleh dari karyawan meliputi: mencari peluang kerja yang lebih baik ditempat lain melalui internet dan kolega c) Keinginan Untuk Keluar berada pada kategori tidak puas dengan persentase $44 \%$, berdasarkan pernyataan data yang diperoleh dari karyawan meliputi: mendapatkan pekerjaan, posisi kerja, dan mendapatkan kompensasi yang lebih besar dari tempat lain yang dimana hal ini menjadi pertimbangan untuk keluar.

[10]Turnover Intention ialah kecendrungan pembawaan yang telah adapada diri karyawan dimana ada hasrat untuk mencari peluang kerja baru ditempat new, disertai planning untuk meninggalkan kerjaan lama dalamtenggang waktu 3 bulan, 6 bulan,maupun 1 tahun yang akan dating. Variabel Turnover Intention di Royal Denai Hotel Group berada pada kategori tidak baik, diharapkan kepada pihak perusahaan Royal Denai Hotel Group untuk memperhatikan dan meningkatkan faktor-faktor yang dapat mempengaruhi Turnover Intention.

\section{Pengaruh Kompensasi terhadap Turnover Intention Karyawan Di Royal Denai Hotel Group Bukittinggi}

Hasil uji Regresi linear sederhana didapatkan F hitung 8.969 dengan signifikan $0,000<0,05$ diartikan bahwa Kompensasi (X) berpengaruh secara signifikan terhadap Turnover Intention $(\mathrm{Y})$, maka Ha diterima.

Kemudian koefisien determinasi diperoleh $\mathrm{R}$ square 0,792, maksudnya kontribusi antara kompensasi dan Turnover Intention adalah sebesar 79\% dengan $21 \%$ ditentukan oleh faktor lain. Kompensasi berpengaruh terhadap Turnover Intention sebesar $79 \%$ karena indikator Kompensasi adalah tingkat gaji, reward, intensif, dan tunjangan dapat mempengaruhi pemberian Kompensasi karyawan sehingga dapat disimpulkan semakin baik kompensasi yang tersedia maka dapat meningkatkan pemberian kompensasi untuk meminimalisir turnover intention yang terjadi .

\section{Kesimpulan}

1. Variabel X (Kompensasi) indikator sudah ditentukan menunjukan secara keseluruhan dengan nilai persentase sebesar 65\% berada pada 53,35 - <66,65 termasuk kategori kurang baik.

2. Variabel Y (Turnover Intention) dari indikator yang sudah ditentukan menunjukkan secara keseluruhan dengan nilai persentase sebesar $46 \%$ berada pada $40-<50$ termasuk kategori kurang baik.

3. Adanya hubungan yang signifikan antara X terhadap $\mathrm{Y}$ pada Karyawan di Royal Denai Hotel Group Bukittinggi sebesar $79 \%$ sedangkan 21\% dipengaruhi oleh faktor lainnya. 


\section{DAFTAR PUSTAKA}

[1] S. Janti, “ Prosiding Seminar Nasional Aplikasi Sains \& Teknologi (SNAST) 2014 Yogyakarta, 15 November 2014 ISSN: 1979-911X, " Snast, no. November, pp. 211-216, 2014.

[2] Chair, iraMeirina. Heru Pramudia.2017.Hotel Room DivisionManagement. Prenadamedia Group:Kencana

[3] J. Lauren, “ Pengaruh Kompensasi Dan Komitmen Organisasional Terhadap Turnover Intention Dengan Kepuasan Kerja Sebagai Variabel Mediasi Pada Karyawan, ” Agora, vol. 5, no. 1, p. 56858, 2017.

[4] Wahyuni, A. S., Zaika, Y., \& Anwar, R.(2015). Analisisfaktor-faktor yang mempengaruhi turnover intention (keinginan berpindah) karyawan pada perusahaan jasa konstruksi. Rekayasa Sipil, 8(2), 89-95

[5] D. Widjaja, S. Kristiani, and E. Marcella, " Faktor-Faktor yang Mempengaruhi Turnover Intention Job Hopper di Industri Perhotelan di Indonesia, ” J. PETRA, vol. 6, no. 2, pp. 90-101, 2018.

[6] N. E. Putri, D. Iskandar, and I. N. Sudita, “ Pengaruh Kepuasan Gaji, Kepuasan Kerja,dan Komitmen Organisasional Terhadap Turnover Intention ( Studi Kasus Pada Bidan Praktek Swasta Di Kabupaten Sleman ), " urnal Bisnis dan Ekon., vol. 14, no. 1, pp. 89-99, 2015, doi: 10.25124/jmi.v14i2.356.

[7] B. G. Alhogbi, " No Title No Title, " J. Chem. Inf. Model., vol. 53, no. 9, pp. 21-25, 2017, [Online]. Available: http://www.elsevier.com/locate/scp.

[8] Sugiyono," Metode Penelitian," Metod.Penelit.,2015

[9] P. Katidjan, S. Pawirosumarto, and A. Isnaryadi, “Pengaruh Kompensasi Pengembangan Karir dan Komunikasi terhadap Kinerja Karyawan Purwanto S. Katidjan, Suharno Pawirosumarto, dan Albertus Isnaryadi Universitas Mercu Buana Jakarta," vol. VII, no. 3, pp. 429-446, 2017.

[10] A. Fathoni and M. M. Minarsih, " Organizational Commitment and Compensation For. " 